\title{
Scaling of growth rate and mortality with size and its consequence on size spectra of natural microphytoplankton assemblages in the East China Sea
}

\author{
F. H. Chang ${ }^{1}$, E. C. Marquis ${ }^{2}$, C. W. Chang ${ }^{3}$, G. C. Gong ${ }^{4,5,6}$, and C. H. Hsieh ${ }^{1,2}$ \\ ${ }^{1}$ Institute of Ecology and Evolutionary Biology, National Taiwan University, Taipei, 10617, Taiwan \\ ${ }^{2}$ Institute of Oceanography, National Taiwan University, Taipei, 10617, Taiwan \\ ${ }^{3}$ Taiwan International Graduate Program (TIGP) - Earth System Science Program, Academia Sinica and National Central \\ University, Research Center for Environmental Changes, Academia Sinica, Taipei, 11529, Taiwan \\ ${ }^{4}$ Institute of Marine Environmental Chemistry and Ecology, National Taiwan Ocean University, Keelung, 20224, Taiwan \\ ${ }^{5}$ Center of Excellence for Marine Bioenvironment and Biotechnology, National Taiwan Ocean University, Keelung, \\ 20224, Taiwan \\ ${ }^{6}$ Taiwan Ocean Research Institute, National Applied Research Laboratories, Kaohsiung, 852, Taiwan
}

Correspondence to: C. H. Hsieh (chsieh@ntu.edu.tw)

Received: 29 October 2012 - Published in Biogeosciences Discuss.: 21 November 2012

Revised: 27 May 2013 - Accepted: 29 June 2013 - Published: 5 August 2013

\begin{abstract}
Allometric scaling of body size versus growth rate and mortality has been suggested to be a universal macroecological pattern, as described by the metabolic theory of ecology (MTE). However, whether such scaling generally holds in natural assemblages remains debated. Here, we test the hypothesis that the size-specific growth rate and grazing mortality scale with the body size with an exponent of $-1 / 4$ after temperature correction, as MTE predicts. To do so, we couple a dilution experiment with the FlowCAM imaging system to obtain size-specific growth rates and grazing mortality of natural microphytoplankton assemblages in the East China Sea. This novel approach allows us to achieve highly resolved size-specific measurements that would be very difficult to obtain in traditional size-fractionated measurements using filters. Our results do not support the MTE prediction. On average, the size-specific growth rates and grazing mortality scale almost isometrically with body size (with scaling exponent $\sim 0.1)$. However, this finding contains high uncertainty, as the size-scaling exponent varies substantially among assemblages. The fact that size-scaling exponent varies among assemblages prompts us to further investigate how the variation of size-specific growth rate and grazing mortality can interact to determine the microphytoplankton size structure, described by normalized biomass size spectrum (NBSS),
\end{abstract}

among assemblages. We test whether the variation of microphytoplankton NBSS slopes is determined by (1) differential grazing mortality of small versus large individuals, (2) differential growth rate of small versus large individuals, or (3) combinations of these scenarios. Our results indicate that the ratio of the grazing mortality of the large size category to that of the small size category best explains the variation of NBSS slopes across environments, suggesting that higher grazing mortality of large microphytoplankton may release the small phytoplankton from grazing, which in turn leads to a steeper NBSS slope. This study contributes to understanding the relative importance of bottom-up versus top-down control in shaping microphytoplankton size structure.

\section{Introduction}

Growth and mortality represent two key ecological processes of organisms. The phytoplankton community growth rate is determined not only by temperature and resource availability but also by the size composition of the community. Temperature effects have been known to be positive on the maximum phytoplankton growth rate (Bissinger et al., 2008; Eppley, 1972). The effects of resource availability, such as 
nutrients and light, on phytoplankton population growth depend on body size (Finkel, 2001; Finkel et al., 2004; Irwin et al., 2006). In general, large phytoplankton exhibit a lower photosynthesis rate because of the package effect (Berner et al., 1989) and a lower nutrient uptake rate because of lower surface-to-volume ratio (Kiørboe, 1993). However, when light and nutrients are sufficient, large individuals could have competitive advantages over small individuals (Maguer et al., 2009) due to their low susceptibility to light damage and higher carbon-specific photosynthesis rates (Cermeño et al., 2005; Key et al., 2010).

The relationship between body size and population growth rate has recently been described using the metabolic theory of ecology (MTE) (Brown et al., 2004). According to MTE, the temperature-corrected size-specific population growth rate scales allometrically with its body size, with an exponent of $-1 / 4$ (Brown et al., 2004). Although this $-1 / 4$ scaling exponent has been observed in compiled data from freshwater and marine phytoplankton (Edwards et al., 2012; Litchman et al., 2007), other studies using natural assemblages from open ocean and coastal regions have showed that the phytoplankton growth rate scales isometrically with body size (Marañón, 2008; Marañón et al., 2007; Huete-Ortega et al., 2012) or exhibits a parabolic relationship with body size (Chen and Liu, 2010). However, reviews suggest that the scaling exponents vary from $-1 / 3$ to 0 (Glazier, 2005, 2010). Clearly, linkage between growth rate and body size of phytoplankton needs further investigation.

In addition to growth rate, mortality is another important factor influencing phytoplankton dynamics. The mortality rate generally is determined by both intrinsic and extrinsic mechanisms. The intrinsic mechanism attributes to the individual metabolic rate, which is determined primarily by body size and temperature (Brown et al., 2004; Savage et al., 2008). In contrast, the extrinsic mechanism refers to other death causes such as disease, predation, or accident (Ricklefs, 1998). According to MTE, mass-specific intrinsic mortality rate should scale with body size with a $-1 / 4$ exponent, because of metabolic constraints, and indeed such a scaling relationship has been reported empirically (Hendriks, 2007; Marba et al., 2007). However, the relationship between extrinsic mortality and body size is not well studied. Interestingly, McCoy and Gillooly (2008) compiled comprehensive empirical data and reported that the total mortality (i.e. the sum of both intrinsic and extrinsic mortality) of organisms also scales with body size with a $-1 / 4$ exponent, which suggests that either extrinsic mortality also scales with body size with $a-1 / 4$ exponent or extrinsic mortality is independent of body size.

For microphytoplankton, the major extrinsic mortality comes from microzooplankton grazing (Calbet and Landry, 2004). Two mechanisms have been proposed to explain the microzooplankton grazing behaviour. The first mechanism proposes that microzooplankton select phytoplankton that grow faster (Lie and Wong, 2010), while the second mech- anism suggests microzooplankton prefer phytoplankton that are small in size (Froneman and McQuaid, 1997; Zhang et al., 2005). The debate could stem from the strong correlation between being small and having fast growth rates according to MTE (Brown et al., 2004). In addition, the confusion could result from the low resolution in defining the size class of phytoplankton (Montagnes et al., 2008). In order to shed light on the unclear pattern of phytoplankton grazing mortality, detailed and thorough size-specific studies are needed.

The knowledge of size-specific growth rate and grazing mortality would directly contribute to understanding the variations of phytoplankton size structure across environments. While this is intuitive, rarely have the studies of phytoplankton size structure been carried out simultaneously with sizespecific growth rate and grazing mortality measurements. Rather, most studies focused on correlation analyses to link phytoplankton size structures with environmental variables. For instance, studies have shown that high nutrients generally lead to prevalence of large phytoplankton (Cavender-Bares et al., 2001; Huete-Ortega et al., 2011; Juhl and Murrell, 2005; Reul et al., 2005); oligotrophic conditions, by contrast, result in predominance of small phytoplankton (Irwin et al., 2006; $\mathrm{Li}, 2002)$. In addition, high temperature usually favours the dominance of small phytoplankton (Agawin et al., 2000; Yvon-Durocher et al., 2011). Worth noting is that, since nutrient supply often covaries with temperature in natural environments (Marañón et al., 2012), it is not easy to distinguish the effects of nutrients from temperature. These studies, however, focus on the size-structure variations with respect to environmental factors instead of directly measuring the phytoplankton growth rate and grazing mortality (Moran et al., 2010). While other studies focused on the selective grazing behaviour of microzooplankton and inferred the potential effect on the phytoplankton size structure, they did not measure the phytoplankton size structure together with feeding experiments (Calbet et al., 2008; Teixeira et al., 2011). Moreover, while size-specific phytoplankton responses were examined in modelling research to explain the increase of large phytoplankton with nutrient concentration (Irwin et al., 2006; Verdy et al., 2009), empirical studies on size-specific growth rate and grazing mortality would help clarify the mechanisms affecting the phytoplankton size structure.

Phytoplankton size structure is commonly quantified using the slope of normalized biomass size spectrum (NBSS) (Platt and Denman, 1977). There is an obvious linkage of sizespecific growth rate and grazing mortality with the NBSS slope. The NBSS slope can vary among assemblages because of variation in the relative growth rate and grazing mortality of small versus large individuals among assemblages. For example, suppose there are two hypothetical stations, A and B. Assuming in station A, compared to station B, small individuals show comparable growth rate but higher grazing mortality to the large individuals, the NBSS slope in station A should be shallower than that in B. More specifically, the NBSS slope can vary among environments (stations) if 
the scaling of size-specific growth rate or grazing mortality varies among environments.

Here, we focus on microphytoplankton, a community that has never been studied for its size-specific growth rate and grazing mortality in natural assemblages. We have two objectives. First, we test if the MTE is applicable to natural microphytoplankton assemblages. Specifically, we conduct a within-assemblage analysis to test whether the size-specific growth rate and grazing mortality generally scale with the body size with an exponent of $-1 / 4$ after temperature correction. Our second objective is to investigate how the variation of microphytoplankton size structure (NBSS slope) among assemblages can be explained by the relative growth rate and grazing mortality of small versus large individuals among assemblages. Specifically, we test the hypotheses that the variation of microphytoplankton NBSS slopes is determined by (1) differential grazing mortality of large versus small individuals, (2) differential growth rate of large versus small individuals, or (3) combinations of these scenarios.

\section{Methods}

\subsection{Sites descriptions}

We carried out our experiments in the East China Sea (ECS), which is an ideal region to study microzooplanktonphytoplankton interactions because of its strong environmental gradient. The ECS is influenced by the eutrophic discharge from the Yangtze River in the coastal region and the oligotrophic Kuroshio Current in the offshore area (Gong et al., 1996, 2003). Previous studies have indicated a declining gradient in nutrient concentration from the coastal area to offshore (Zhang et al., 2007). The phytoplankton community structure and the interactions between phytoplankton and zooplankton in the ECS have been shown to vary across this nutrient gradient (Chan et al., 2003; Chang et al., 2009; Jiao et al., 2002; Tsai et al., 2011). These studies focused on pico- and nano-phytoplankton rather than microphytoplankton. However, microphytoplankton could also play an important role in biogeochemical processes in the ECS.

\subsection{Sampling}

We carried out 26 sets of dilution experiments in the ECS (Fig. 1) from May 2010 to October 2011 during 7 cruises on board a research vessel (Table A1). Temperature and salinity profiles were recorded with a SeaBird CTD profiler (SBE9/11 plus, SeaBird Inc., USA). The photosynthesis active radiation (PAR) profile was measured with a quantum scalar irradiance meter ( $4 \pi$ collector; Biospheric Inc., USA) attached to the CTD profiler. Nutrients (nitrate, phosphate, and silicate) and chlorophyll $a(\mathrm{chl} a)$ concentrations were measured from water samples collected with Go-Flo bottles at 4 to 6 depths depending on stations. The analytic methods used for nutrients and chl $a$ are described in Gong et

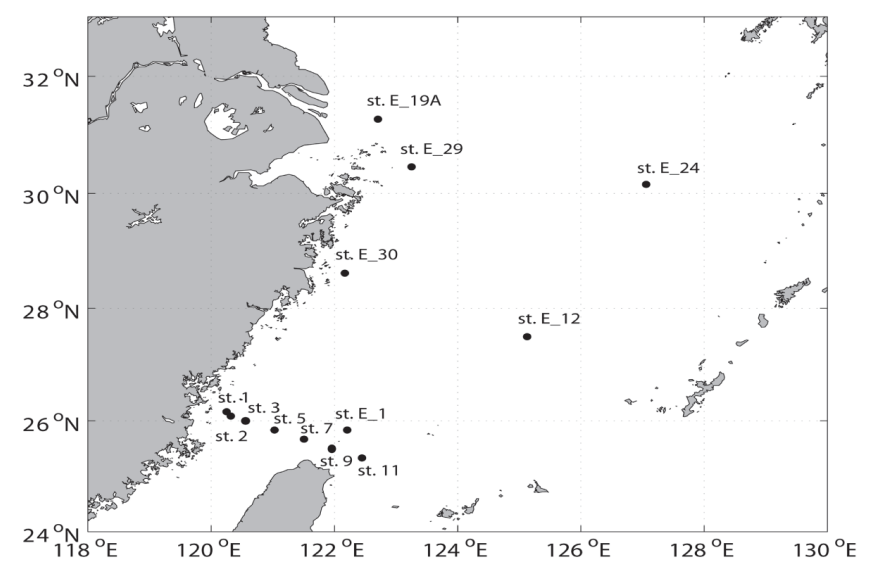

Fig. 1. Map illustrating experimental stations in the East China Sea.

al. (2000). These environmental measurements for each station were integrated over the entire euphotic zone using discrete gradient integration method, and the integrated average was used for analyses (Table A1 in Supplement A).

\subsection{Dilution experiments}

To investigate the growth and mortality rate of microphytoplankton, dilution experiments were conducted (Landry and Hassett, 1982; Landry et al., 1995). All incubation bottles, tubes, and carboys were acid-rinsed first with $10 \% \mathrm{HCl}$ and then with distilled water. Carboys were rinsed with ambient seawater before each experiment. For each set of experiments, $40 \mathrm{~L}$ of whole seawater (WSW) were collected at the $10 \mathrm{~m}$ depth using a CTD-rosette system with Go-Flo bottles. Another $20 \mathrm{~L}$ of seawater were filtered through a $0.2 \mu \mathrm{m}$ filter membrane (Millipore $144 \mathrm{~mm}$ ) with a peristaltic pumping system to obtain particle-free sea water (FSW). We gently mixed the FSW and WSW in $2.4 \mathrm{~L}$ polycarbonate bottles to prepare the four dilution treatments, 25, 50, 75, and $100 \%$ of WSW with artificial nutrient amendment and another $100 \%$ WSW without amendment. Treatments with artificial nutrient amendment received $6.2 \mathrm{~mL}$ of Guillard's (F/2) Marine Water Enrichment Solution (cat. No. G0154) and $20 \mu \mathrm{ml} \mathrm{NH} \mathrm{N}_{4} \mathrm{Cl}$ (nutrient added into each incubation bottle: $\left.3 \mu \mathrm{M} \mathrm{NO} 3 ; 0.12 \mu \mathrm{M} \mathrm{PO}_{4} ; 0.36 \mu \mathrm{M} \mathrm{SiO}_{4} ; 3 \mu \mathrm{M} \mathrm{NH} 4\right)$. Three of five treatments of the dilution series $(25 \%, 50 \%$, and $75 \%$ WSW) were prepared in duplicate and the other two (100\% WSW with and without nutrient amendment) in triplicate. All the $2.4 \mathrm{~L}$ polycarbonate bottles were placed in a large opaque incubation tank with a lid for $24 \mathrm{~h}$ of on-deck incubation.

Incubation tanks were filled with constantly circulating surface seawater along the cruise, with temperature measured periodically. During the incubation, we maintained the natural light cycle as closely as possible to avoid light limitation by unveiling the lid before dawn and veiling it after dusk to avoid artificial light from the research vessel. Samples 
were collected from the WSW before incubation $\left(T_{0}\right)$ and from each incubation bottle after incubation $\left(T_{24}\right)$ for FlowCAM analyses. The mortality of phytoplankton under nutrient amendment was assumed to be mainly due to grazing rather than intrinsic processes, such as starvation. In our experiments, resource limitation was not a concern for phytoplankton growth and mortality in testing MTE because our experiments were carried out with nutrient amendment and on board a research vessel where light was presumably not limited between the hours of dawn and dusk.

\subsection{FlowCAM analysis}

In this study, we developed a novel approach to measure the phytoplankton size-specific growth and grazing mortality using the Flow Cytometer And Microscope (FlowCAM), which is an automatic sampling device that has been shown to exhibit high accuracy and efficiency in measuring phytoplankton size structure (Alvarez et al., 2011) and in zooplankton grazing experiments (Ide et al., 2008). This new approach overcomes the deficiency in traditional sizefractionated chlorophyll measurements (Calbet et al., 2001, 2008; Calbet, 2008; Lessard and Murrell, 1998; Reckermann and Veldhuis, 1997), which cannot provide satisfactory size resolution. Combining the detailed size information acquired from the FlowCAM and dilution technique, we were able to measure the size-specific growth and mortality rate of microphytoplankton with high resolution ranging from 10 to $300 \mu \mathrm{m}$.

We processed fresh samples with the FlowCAM on board the research vessel. All fresh samples were taken from the initial undiluted WSW $\left(T_{0}\right)$ before incubation and the bottles at the end of incubation $\left(T_{24}\right)$. However, due to time limitation on the boat, each sample was processed by passing a water sample of $6 \mathrm{~mL}$ or $18 \mathrm{~min}$, whichever came first. The objective used for on-boat analysis is $4 \times$ and the flow cell used was $300 \mu \mathrm{m}$ in thickness following the operations manual. This combination allowed all the particles to pass through. Images of particle sizes ranging from 4 to $500 \mu \mathrm{m}$ ESD (equivalent spherical diameter) were captured by the FlowCAM automatically, while only those ranging from 10 to $300 \mu \mathrm{m}$ ESD were extracted for further analyses. The average number of particles processed and average particle density of triplicates in each sampling station are presented in Table B1 in Supplement B.

To estimate the biomass of microphytoplankton, particles were manually classified into 6 categories: chain-forming diatom, single diatom, naked dinoflagellate, shelled dinoflagellate, colony small cells, and singletons smaller than $20 \mu \mathrm{m}$ ESD. Biovolumes $\left(\mu \mathrm{m}^{3}\right)$ of all microphytoplankton individuals were automatically estimated by the FlowCAM and were then converted into carbon biomass (pg) according to the category-specific conversion equation. The conversion equation is $\mathrm{C}=c \times V^{d}$, where " $\mathrm{C}$ " is the cell carbon (pg), $V$ cell volume $\left(\mu \mathrm{m}^{3}\right), c$ a coefficient, and $d$ the size scaling

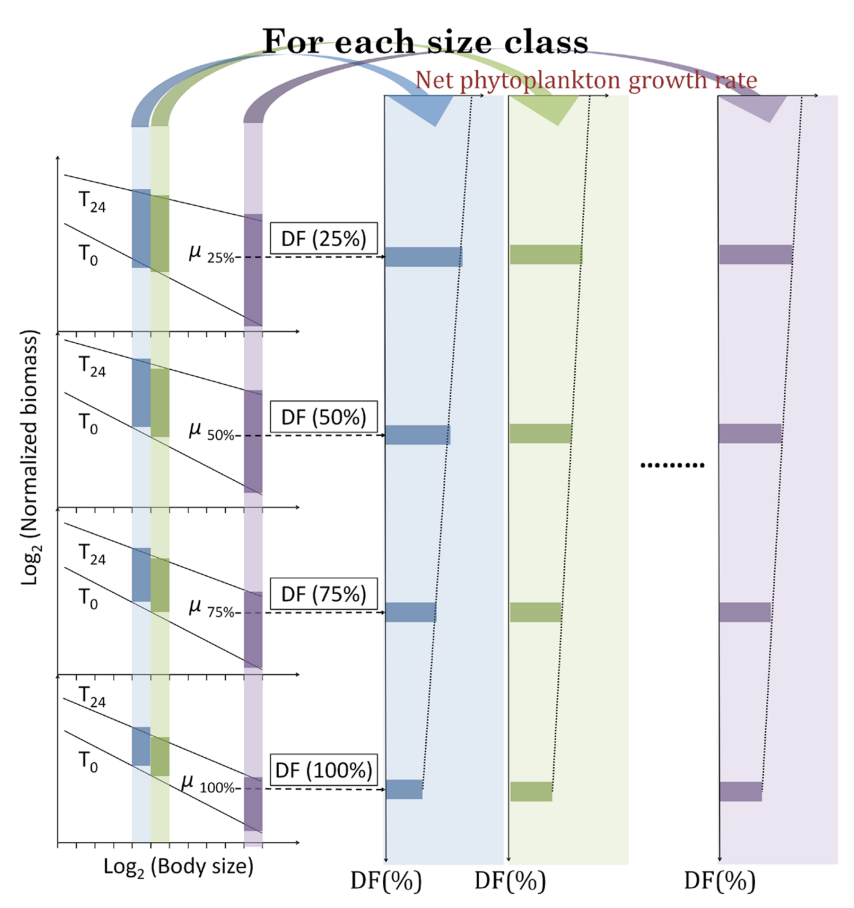

Fig. 2. Schematic illustrating how the size-specific growth rate and grazing mortality for each size class were calculated. Left panel shows the relationship between phytoplankton biomass versus size at $T_{0}$ and $T_{24}$ (black lines) for each dilution factor. Dilution factor (DF) represents the percentage of unfiltered seawater. Right panel illustrates the regression analysis of realized phytoplankton growth rate ( $x$ axis) versus the corresponding dilution factors ( $y$ axis) for each size class. Colours indicate different size classes. By comparing the phytoplankton biomass at $T_{0}$ and $T_{24}$ under different dilution factors for each size class, one can estimate size-specific growth rate and grazing mortality using the regression approach commonly employed in dilution experiments for each size class.

exponent. Both $c$ and $d$ are listed in Marquis et al. (2011). Throughout this paper, we use carbon biomass to represent body size of phytoplankton.

\subsection{Data analysis}

\subsubsection{Calculation of size-specific growth rate and grazing mortality}

To estimate the size-specific growth rate and grazing mortality of microphytoplankton, we first constructed the size spectrum of microphytoplankton at $T_{0}$ and $T_{24}$ (Fig. 2). The normalized biomass size spectra of phytoplankton were employed in this study, and we divided the total biomass of each $\log _{2}$ size class by the width of the respective size class (Platt and Denman, 1977; Sheldon et al., 1972). The microphytoplankton biomass within this range covers 12 orders of magnitude under $\log _{2}$ scale. A $\log _{2}$ scale was used to be in accordance with the standard convention, which keeps the highest size resolution possible. In this manner, we estimated the 
biomass of each size class at $T_{0}$ and $T_{24}$. This new method has an advantage over traditional methods for obtaining sizefractionated chl $a$ measurements, which exhibit difficulties with high-resolution data.

The growth and mortality rates were estimated using a linear regression of realized phytoplankton growth rates of four dilution treatments versus the corresponding dilution factors (\% of WSW). Thus, we could calculate the slope as the grazing mortality $(\mathrm{m})$ and the intercept as the intrinsic phytoplankton growth rate $(\mu)$ (Landry and Hassett, 1982; Landry et al., 1995). The novel and additional calculation here is that, for each size class, we carried out linear regression of realized phytoplankton growth rates on four dilution treatments to estimate size-specific growth rate and grazing mortality (Fig. 2). In addition to $\mu$, we also measured the sizespecific growth rate without nutrient amendment $\left(\mu^{\prime}\right)$. Consequently, the size-specific growth rate with and without nutrient amendment $\left(\mu\right.$ and $\left.\mu^{\prime}\right)$ and grazing mortality $(m)$ of microphytoplankton could be estimated.

\subsubsection{Data pre-treatments}

Before analyses, we performed two pre-treatments. The prerequisite for testing MTE is that the growth rate should not be limited by resources, such as nutrients or light for phytoplankton. Therefore, we used the growth rate measured with nutrient amendment $(\mu)$ after temperature correction for testing the MTE. According to the MTE, the temperature effect on growth rate and mortality should be adjusted (Brown et al., 2004). Thus, the temperature-corrected rate $\left(M_{c}\right)$ was calculated from the measurement $(M)$ following $M_{c}=M \times 10^{E / k T}$, where $E$ is the activation energy (in electronic volts $(\mathrm{eV})), k$ the Boltzmann constant $(8.617 \times 10$ $5 \mathrm{eV} \mathrm{K}^{-1}$ ), and $T$ the absolute temperature in $\mathrm{K}$. The activation energy was set to be $0.32 \mathrm{eV}$ (Allen et al., 2005; LopezUrrutia et al., 2006). Second, for each station, we removed negative size-specific growth rate and grazing mortality for further analyses. Because of the fine scale in size class defined in our study and sampling error, it was possible for certain size classes to exhibit negative size-specific growth or grazing mortality. After removing negative values, 200 out of 312 (12 size classes in each of the 26 stations) size classes (having both positive size-specific growth rate and grazing mortality) were left.

\subsubsection{Scaling of size-specific growth rate and grazing mortality within assemblages (stations)}

To achieve the first objective, we performed a withinassemblage analysis to test whether the $\mu$ and $m$ scale with the body size with an exponent of $-1 / 4$ after temperature correction for each station. We did this using a simple linear regression of size-specific growth rate (or mortality) against size class for each station. To further investigate the general scaling, we pooled data from all stations and used a gen- eralized linear mixed effect model (GLMM) (Bolker et al., 2009) to estimate the average exponent. In GLMM, stations were considered as the random effect to examine whether a general scaling relationship exists within an assemblage. Including stations as a random effect variable removes the possibility for any spurious relationships arising from variation across seasons or space while using data from all stations to increase sample size. We further investigated the scaling of $\mu$ and $m$ on body size for each cruise following the same protocol of GLMM analysis.

\subsubsection{Coupling between size-specific growth rate and grazing mortality}

To further clarify the relationship among microphytoplankton body size, size-specific growth rate, and size-specific grazing mortality, we regressed the size-specific grazing mortality against size-specific growth rate, using GLMM with stations as the random effect. Additionally, to partition out the effect of body size, we performed a linear regression of the residuals from the size-specific grazing mortality GLMM (of size-specific rate versus size with stations as the random effect) against the residuals from size-specific growth rate GLMM. Our aim was to examine if the microphytoplankton grazing mortality and growth rate are coupled together within an assemblage regardless of body size. The size-specific rates analysed here are without temperature correction, and the growth rates used are those measured without nutrient amendments $\left(\mu^{\prime}\right)$, which represents realistic conditions found in nature. Nevertheless, the analysis on $\mu$ reveals qualitatively similar conclusion.

\subsubsection{NBSS slope variation among assemblages}

To achieve our second objective of understanding how the variation of microphytoplankton size structure (NBSS slope) among assemblages can be explained by the relative growth rate and grazing mortality of small versus large individuals among assemblages, we examined whether the variation of NBSS slope across environments was related to the variation of relative growth rate and grazing mortality of small versus large individuals among assemblages. This was motivated by the finding that the size-specific growth rate and grazing mortality scaling vary among stations (see Fig. 3 and Table B2 in Sect. 3.1).

Ideally, we would perform a regression analysis between the NBSS slopes and the scaling exponents across stations. However, estimation of the scaling exponent for each station was subject to high uncertainty for some stations because some size classes needed to be removed due to the negative size-specific growth rate or grazing mortality; after removing these data, the sample size was too small to estimate reliably the scaling exponents. Thus, we binned the size classes into size categories and used them as explanatory variables, instead of using the slope (exponent) of each station directly 
Table 1. Results of the generalized linear mixed effect model (GLMM) linking microphytoplankton size-specific growth rate ( $\mu$ ) and grazing mortality $(m)$ with microphytoplankton body size (biomass). In GLMM, stations were considered as the random effect.

\begin{tabular}{llcr}
\hline Cruise & Coefficient $(95 \%$ confidence interval $)$ & SE & $p$ value \\
\hline Overall GLMM: $\log _{2}(\mu) \sim \log _{2}($ phytoplankton biomass $)$ & + random effect $($ station $)$ \\
\hline Over all & $0.092(0.056,0.123)$ & 0.015 & $<0.001$ \\
Within cruise: & & & \\
May 2010 & $0.175(0.037,0.317)$ & 0.056 & 0.006 \\
Dec 2010 & $0.175(0.111,0.233)$ & 0.026 & $<0.001$ \\
Jun 2011 & $-0.031(-0.059,0.002)$ & 0.013 & 0.025 \\
Jul 2011 & $0.011(-0.059,0.080)$ & 0.027 & 0.692 \\
Aug 2011 & $0.075(-0.013,0.130)$ & 0.032 & 0.026 \\
Sep 2011 & $0.101(-0.014,0.213)$ & 0.053 & 0.070 \\
Oct 2011 & $0.233(0.160,0.318)$ & 0.035 & $<0.001$ \\
\hline Overall GLMM: $\log _{2}(m) \sim \log _{2}($ phytoplankton biomass $)$ & + random effect $($ station $)$ \\
\hline Over all & $0.113(0.054,0.172)$ & 0.030 & $<0.001$ \\
Within cruise: & & & \\
May 2010 & $0.132(-0.104,0.312)$ & 0.093 & 0.169 \\
Dec 2010 & $0.122(-0.060,0.244)$ & 0.078 & 0.133 \\
Jun 2011 & $0.055(-0.051,0.161)$ & 0.055 & 0.328 \\
Jul 2011 & $-0.068(-0.162,-0.000)$ & 0.031 & 0.033 \\
Aug 2011 & $0.078(-0.080,0.256)$ & 0.111 & 0.486 \\
Sep 2011 & $0.271(0.087,0.397)$ & 0.074 & 0.001 \\
Oct 2011 & $0.357(0.265,0.482)$ & 0.050 & $<0.001$ \\
\hline
\end{tabular}

for analysis. Specifically, we binned the smallest four size classes $\left(2^{6}\right.$ to $\left.2^{10} \mathrm{pg}\right)$ into the small size category, the middle four size classes ( $2^{10}$ to $2^{14} \mathrm{pg}$ ) into the medium size category, and the largest four size class $\left(2^{14}\right.$ to $\left.2^{18} \mathrm{pg}\right)$ into the large size category, and calculated the average growth rate and grazing mortality for each category. The growth rates and grazing mortalities of the large and small size category influenced the NBSS slope most, but the rates of medium size category showed no influence. Therefore, only the sizespecific growth rate measured without nutrient amendments and grazing mortality of small and large size category ( $\mu_{\mathrm{S}}^{\prime}$, $\mu_{\mathrm{L}}^{\prime}, m_{\mathrm{S}}$, and $\left.m_{\mathrm{L}}\right)$ were investigated. Note here we used the growth rates measured without nutrient amendments $\left(\mu^{\prime}\right)$ so that we investigated presumably the in situ growth rates. To represent the effects from real measurements, the sizespecific growth rate and grazing mortality values were not corrected by temperature.

For the correlation analysis, considering the strong correlation between the growth rate and grazing mortality (Barnes et al., 2011; Chen et al., 2009; Landry et al., 2000; Murrell et al., 2002), we used univariate linear models instead of stepwise selection to avoid the issue of colinearity. We analysed 9 univariate regression models. The independent variables of these 9 models include 2 growth rates and 2 grazing mortalities as described above $\left(\mu_{\mathrm{S}}^{\prime}, \mu_{\mathrm{L}}^{\prime}, m_{\mathrm{S}}\right.$, and $\left.m_{\mathrm{L}}\right), 2$ grazing impacts $\left(I_{\mathrm{S}}^{\prime}\right.$, and $I_{\mathrm{L}}^{\prime}$ where $\left.I^{\prime}=m / \mu^{\prime}\right)$ designed to measure the grazing pressures of 2 size categories without nutrient amendments, and 3 ratios $\left(\mu_{\mathrm{S}}^{\prime} / \mu_{\mathrm{L}}^{\prime}, m_{\mathrm{S}} / m_{\mathrm{L}}\right.$, and $\left.I_{\mathrm{S}}^{\prime} / I_{\mathrm{L}}^{\prime}\right)$ de- signed to explore the relative importance of the small versus large size categories in terms of the size-specific growth rate, grazing mortality and grazing impact.

In these analyses, we focused only on biologically possible effects of each independent variable on the NBSS slope (i.e. we tested whether the relationship significantly follows the biological expectation using one-tail tests) (Table 2). For example, relatively higher growth rate of small over large phytoplankton category $\left(\mu_{\mathrm{S}}^{\prime} / \mu_{\mathrm{L}}^{\prime}\right)$ was expected to decrease (steepen) the NBSS slope, and it was not possible to produce directly a flatter size-spectral slope; thus, the anticipated correlation of $\mu_{\mathrm{S}}^{\prime} / \mu_{\mathrm{L}}^{\prime}$ versus NBSS slope was negative (Table 2).

\subsubsection{Environmental effects on the variation of NBSS slopes among assemblages (stations)}

We conducted redundancy analysis (Legendre and Legendre, 1998) to examine if the environmental factors (explanatory matrix) could explain the 9 independent variables (response matrix). This analysis links the environmental conditions to size-specific growth rate and grazing mortality, which subsequently affect the NBSS slope. The environmental factors include nitrite + nitrate concentration $(\mathrm{N})$, photosynthesis active radiation (PAR), phosphate concentration $(\mathrm{P})$, salinity $(S)$, silicate concentration $(\mathrm{Si})$, and temperature $(T)$. 

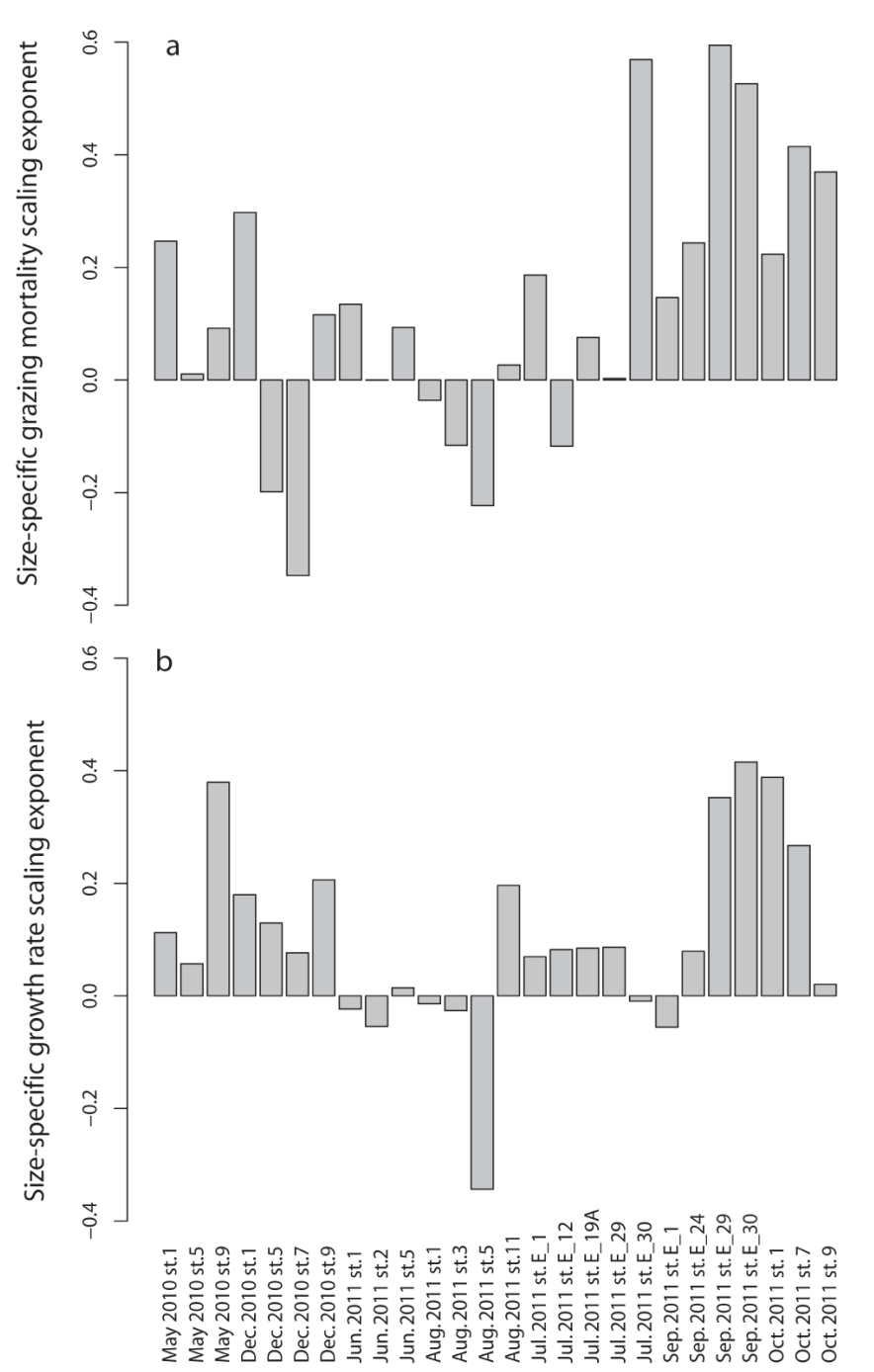

Fig. 3. Barplot showing the scaling exponent of size-specific growth rate (a) and size-specific grazing mortality scaling (b) of each station. The average of growth rate scaling is 0.103 , and the average grazing mortality scaling is 0.128 . The bootstrapped $95 \%$ confidence interval is 0.040 to 0.164 for the growth rate scaling and 0.040 to 0.219 for the grazing mortality scaling.

\subsubsection{Further analyses to test the robustness of the results}

Because some stations could show non-significant regression results in dilution experiments, we prepared the following 4 reduced data sets to test the robustness of our results. For the first reduced data set, we removed the size classes with the regression $p$ value larger than 0.25 in dilution experiments, regardless of whether the regression $p$ value in dilution experiments for the whole community is high or low. To prepare the second reduced data set, we removed the stations with the regression $p$ value for the whole community larger than 0.25 . For the third set, we first removed the stations with the regression $p$ value for the whole community larger than
0.25 and then removed the size classes with the regression $p$ value larger than 0.25 in the remaining stations. The fourth set is prepared by removing the stations with average regression $p$ value of all size classes larger than 0.25 in that station. All the 4 reduced data sets were analysed in the same manner as the procedure used for the whole data set.

\section{Results}

\subsection{Scaling of size-specific growth rates $(\mu)$ and grazing mortality $(m)$}

We find that size-specific growth rate $(\mu)$ and size-specific grazing mortality $(m)$ scaling vary among stations (Fig. 3; Table B2). The average scaling exponent of $\mu$ for all 26 stations is 0.103 , and the $95 \%$ confidence interval ranges from 0.040 to 0.164 . The average scaling exponent of $m$ for all 26 stations is 0.128 , and the $95 \%$ confidence interval ranges from 0.040 to 0.219 .

Pooling all stations and using GLMM to examine the general scaling reveal that, in general, the size-specific growth rate $(\mu)$ and grazing mortality $(m)$ scale almost isometrically with body size (Table 1). In the GLMM results, the withinassemblage scaling exponent was 0.092 for size-specific growth rate $(\mu)$ and 0.113 for size-specific grazing mortality $(m)$ (Table 1). In terms of size-specific growth rate scaling, all cruises exhibit significant size-specific growth rate scaling with body size, except the cruises in July and September 2011. Among all the significant scaling cruises, one negative scaling exponent $(-0.031)$ is found in June 2011. In terms of size-specific grazing mortality, the scalings on the cruise of September (0.271) and October (0.357) 2011 exhibit a positive scaling exponent, while scaling on the cruise of July 2011 (-0.068) shows a negative scaling exponent. The other 4 cruises reveal non-significant scaling exponents. The results remain qualitatively the same when using the 4 reduced data sets (Table $\mathrm{C} 1$ ). In addition, the conclusion on size-specific growth rate and grazing mortality scaling does not change when we remove the "chain-forming diatom" or "colony small cells" category (Table C1).

\subsection{Coupling between size-specific growth rates $\left(\mu^{\prime}\right)$ and grazing mortality $(m)$}

Because phytoplankton growth rate could affect zooplankton grazing (Lie and Wong, 2010; Safi et al., 2007), we further examined the correlation between phytoplankton sizespecific growth rate $\left(\mu^{\prime}\right)$ and grazing mortality $(m)$. The correlation between the size-specific growth rate and mortality is significant $(\mathrm{GLMM}$ slope $=0.668 ; p<0.001)$ when the whole microphytoplankton community across size range was analysed with stations as the random effect (Fig. 4a). Moreover, to partition out the effects from body size as well as station, we regressed the residuals from size-specific grazing mortality GLMM against the residuals from size-specific 
Table 2. Results of univariate correlation analysis examining the relationship between NBSS slopes versus size-specific growth rates, mortality, grazing impacts, and the ratio of small versus large size category for these variables. The subscript ( $\mathrm{S}$ or L) indicates the size category (small or large). $\mu^{\prime}$ represents size-specific growth rates measured without nutrient amendment; $m$ represents size-specific grazing mortality; $I^{\prime}$ represents grazing impact measured without nutrient amendment $\left(I^{\prime}=m / \mu^{\prime}\right)$. Biological anticipations represent the expected positive $(+)$ or negative $(-)$ relationship between each variable versus size spectral slopes, according to biological reasoning. The effect (coefficient) of each independent variable on NBSS slopes was tested against the biological anticipation using one-tail tests.

\begin{tabular}{lllrr}
\hline & $\begin{array}{l}\text { Independent } \\
\text { variables }\end{array}$ & $\begin{array}{l}\text { Biological } \\
\text { anticipation }\end{array}$ & Coefficient & $p$ value \\
\hline Model 1 & $m_{\mathrm{S}}$ & + & 0.172 & 0.291 \\
Model 2 & $m_{\mathrm{L}}$ & - & -0.017 & 0.486 \\
Model 3 & $\mu_{\mathrm{S}}^{\prime}$ & - & 0.238 & 0.988 \\
Model 4 & $\mu_{\mathrm{L}}^{\prime}$ & + & -0.040 & 0.115 \\
Model 5 & $I_{\mathrm{S}}^{\prime}$ & + & -0.283 & 0.956 \\
Model 6 & $I_{\mathrm{L}}^{\prime}$ & - & 0.013 & 0.549 \\
Model 7 & $m_{\mathrm{S}} / m_{\mathrm{L}}$ & + & 0.348 & $0.026^{*}$ \\
Model 8 & $\mu_{\mathrm{S}}^{\prime} / \mu_{\mathrm{L}}^{\prime}$ & - & 0.593 & 0.999 \\
Model 9 & $I_{\mathrm{S}}^{\prime} / I_{\mathrm{L}}^{\prime}$ & + & -0.023 & 0.722 \\
\hline
\end{tabular}

* Indicates the model that gives a biologically reasonable and significant result.

growth rate GLMM to investigate if the grazing mortality truly depends on growth rate. The resulting regression slope is 0.708 ( $p<0.001$, Fig. 4b). Thus, the microphytoplankton grazing mortality and growth rate are coupled, and the grazing mortality could depend on growth rate but not on microphytoplankton body size. Such grazing-growth coupling exists in all the 4 reduced data sets and 2 data sets without "chain-forming diatom" or "colony small cells" category (Table C1).

\subsection{Relative size-specific grazing mortality $\left(m_{\mathrm{S}} / m_{\mathrm{L}}\right)$ explains the variation of the NBSS slope among assemblages}

Results of our 9 univariate models indicate that the NBSS slope is only significantly related to the relative grazing mortality $\left(m_{\mathrm{S}} / m_{\mathrm{L}}\right)$ and the relationship is positive $(p<0.05$, Table 2; Fig. D1). When using the 6 reduced data sets (4 reduced data sets and 2 data sets without "chain-forming diatom" or "colony small cells" category), the relative grazing mortality $\left(m_{\mathrm{S}} / m_{\mathrm{L}}\right)$ remains the only significant variable explaining the NBSS slope (Table C2).

The growth rate and mortality of small versus large individuals are further linked with the environmental factors using redundancy analysis, $\operatorname{RDA}(r=0.506 ; p=0.061$; Fig. 5). The first axis of RDA explains $46.13 \%$ of the variation, and the second axis explains $2.39 \%$. The first axis is associated with $\mu_{\mathrm{L}}^{\prime}$ and $m_{\mathrm{L}}$ and is mainly positively driven by phosphate concentrations. Thus, the RDA biplot (Fig. 5)
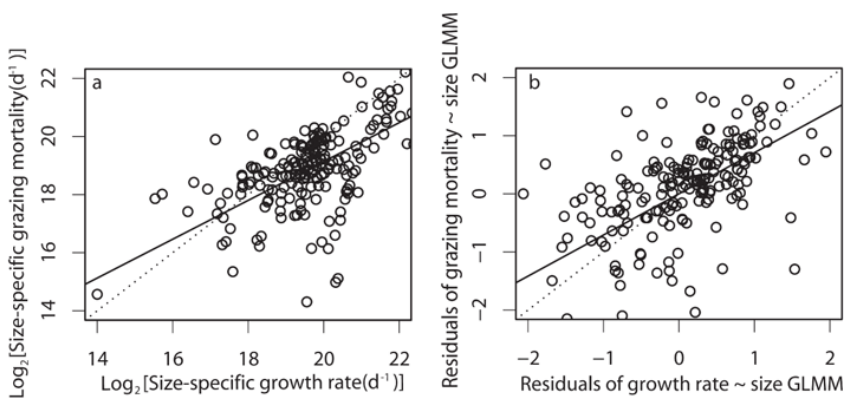

Fig. 4. Scatter plot of $\log _{2}$ transformed size-specific grazing mortality $(m)$ versus growth rate $\left(\mu^{\prime}\right)$. Panel a shows the regression between size-specific grazing mortality and size-specific growth rate using GLMM, with stations as the random effect (slope $=0.668$, $p<0.001)$. Panel $\mathrm{b}$ shows the regression between the residuals from the size-specific grazing mortality GLMM against the residuals from the size-specific growth rate GLMM (slope $=0.708, p<$ 0.001 ). The solid line indicates the significant regression line, and the dashed line indicates the diagonal line.

suggests that growth rate and grazing mortality of large individuals are positively correlated with the phosphate concentration.

\section{Discussion}

\subsection{Scaling of size-specific growth rates $(\mu)$ and mortality $(m)$}

The scaling exponent of size-specific growth rate and mortality varies among stations (Fig. 3; Table B2); this finding does not support MTE. This result suggests a universal scaling of size-specific growth rate and mortality may not exist in natural assemblages, as suggested by Glazier (2005). Interestingly, such variation could be used to explain the variation of NBSS slopes among stations (see Sect. 4.3).

Nevertheless, we still tried to estimate the average scaling using GLMM. The results of GLMM suggest a nearly isometric scaling of size-specific growth rate for natural microphytoplankton assemblages in the ECS (Table 1), which provides further evidence against the MTE. In fact, our observed general scaling exponent of 0.092 (result of GLMM) for size-specific growth rate could be converted to 1.092 for individual-specific growth rate. This value is comparable with the reported values of individual-specific metabolic rates observed in other studies, which ranged from 0.9 to 1.2 (Marañón, 2008; Marañón et al., 2007). Moreover, the $95 \%$ confidence interval of the individual-specific scaling exponent we calculated (1.056 to 1.123 ) is comparable to those in Huete-Ortega et al. (2012), where the individualspecific carbon fixation rate is reported to range from 1.03 to 1.32 . Together with the results of other studies showing isometric scaling between individual respiration and body size in other photosynthetic plants (Reich et al., 2006), 


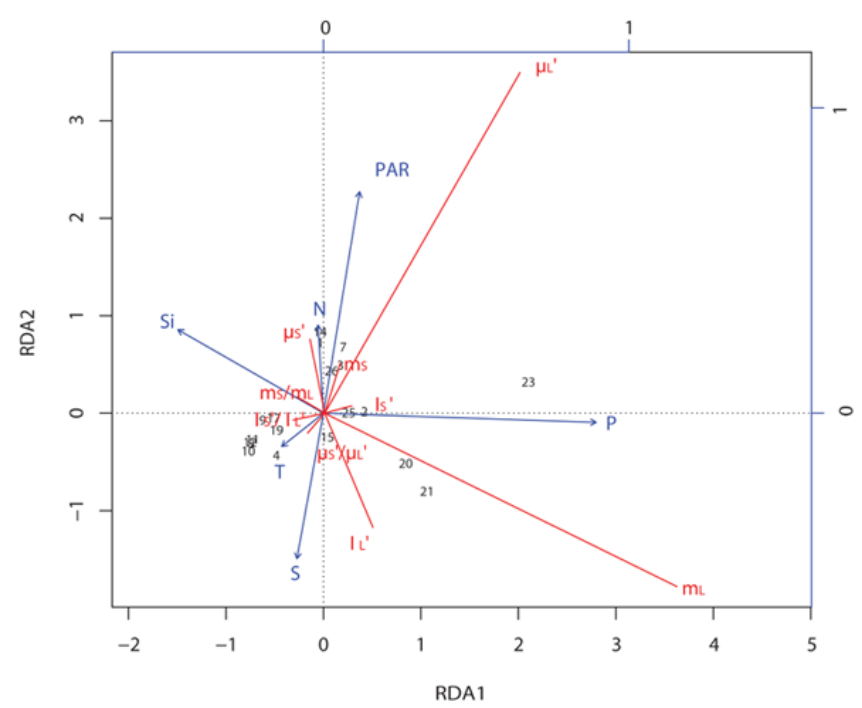

Fig. 5. RDA biplot showing the relationship between the 9 independent variables (red lines; Table 2) and the environmental factors (blue arrows; N: nitrite + nitrate concentration; PAR: photosynthesis active radiation; $\mathrm{P}$ : phosphate concentration; $S$ : salinity; $\mathrm{Si}$ : silicate concentration; $T$ : temperature). The bottom and left-hand scales are for the sampling stations (black numbers; Table A1) and the response variables (red lines); the top and right-hand scales are for the explanatory variables (blue arrows). The environmental factors offer nearly significant explanation of the biological features $(r=0.506 ; p=0.061)$. The first axis explains $46.13 \%$, and the second axis explains $2.39 \%$ of the variance. The first axis is associated with $\mu_{\mathrm{L}}^{\prime}$ and $m_{\mathrm{L}}$ and is mainly positively contributed by phosphate concentrations.

our results cast doubts on the ubiquitous $-1 / 4$ scaling rule between size-specific rates and body size in natural phytoplankton assemblages.

According to MTE, geometric constraints in resource acquisition and transportation network should lead to the observation of allometric scaling ( $-1 / 4$ scaling exponent) (Banavar et al., 2002), but we found a nearly isometric (slightly positive) size-specific growth rate scaling exponent. This could stem from the following features possessed by the larger phytoplankton to overcome their geometric constraints: (1) in terms of nutrient acquisition, large phytoplankton show isometric scaling relationship between nutrient uptake rate and body size (Marañón et al., 2013); (2) in terms of photosynthesis, chl $a$ content of phytoplankton scaled isometrically with body size (Marañón et al., 2007), and (3) the large phytoplankton exhibit higher carbon fixation to chl $a$ ratio (Huete-Ortega et al., 2011). Although the large phytoplankton would exhibit the package effect (Berner et al., 1989), they would be less susceptible to light damage and photoinactivation, which is commonly observed in small phytoplankton (Key et al., 2010). The large phytoplankton could overcome constraints of the transportation network by increasing their vacuole size to elevate storage ability (Latasa et al., 2005; Stolte et al., 1994; Thingstad et al., 2005) and by attaining higher photosynthetic efficiency (Cermeño et al., 2005). The isometric scaling of size-specific growth rate is thus possible under sufficient light and nutrient conditions. However, as the scaling exponent of size-specific growth rate varies among assemblages, we are not certain that our results clearly support the isometric scaling.

For the size-specific grazing mortality $(m)$, the analyses for each station reveal substantial variation among assemblages (Fig. 3b) and the GLMM suggests that, on average, $m$ only slightly positively depends on body size (slope $=0.113$, Table 1). In either case, our findings do not follow the $-1 / 4$ scaling exponent as suggested by MTE. However, MTE predicts a $-1 / 4$ scaling exponent for intrinsic mortality, but not for extrinsic mortality. Again, the mortality estimated from our experiments mainly comes from grazing but not intrinsic processes. If we accept the results of GLMM (showing a scaling exponent close to 0 ), we may consider that the grazing mortality of microphytoplankton may be independent of body size.

Independence of size-specific grazing mortality to body size might have implications on the scaling of phytoplankton total mortality rate. Previous metaanalysis indicates that the phytoplankton total mortality rate (including both intrinsic and extrinsic mortality) shows a $-1 / 4$ power-law relationship between size-specific mortality and body size (McCoy and Gillooly, 2008). Given that the grazing mortality is independent of body size, we suggest that the $-1 / 4$ scaling of total mortality versus body size of phytoplankton is to a large extent determined by the intrinsic processes. Our results suggest that the extrinsic processes (e.g. grazing) may be independent of body size and may not contribute significantly to affect the scaling of mortality in microphytoplankton. However, our results do not clearly support the independence of size-specific mortality and body size because the scaling exponent varies among assemblages.

The coupling of $m$ with $\mu^{\prime}$ (Fig. 4b) and the nonsignificant relationship of the residuals from $m-\mu^{\prime}$ GLMM regressed against body size ( $p=0.693)$ lead us to conclude that the size-specific grazing mortality mainly depends on the size-specific growth rate but not on body size, which is consistent with previous studies indicating that the microphytoplankton size-specific grazing mortality is size-independent (Gutiérrez-Rodríguez et al., 2009, 2011; McManus et al., 2007). In conclusion, microphytoplankton growth rate might be the most essential characteristic influencing the zooplankton prey selection behaviour (Burkill et al., 1987; Gaul and Antia, 2001; Lie and Wong, 2010; Strom, 2002; Strom and Welschmeyer, 1991), at least in the ECS. Nevertheless, we still caution our interpretation because body size and sizespecific growth rates show a significant, however small, positive relationship (Table 1). 


\subsection{The relative grazing mortality of small to large microphytoplankton $\left(m_{\mathrm{S}} / m_{\mathrm{L}}\right)$ determines the microphytoplankton NBSS slope}

Only the relative grazing mortality of small over large size category $\left(m_{\mathrm{S}} / m_{\mathrm{L}}\right)$ among our 9 univariate models (Table 2; Fig. D1) can explain the variation of NBSS slopes among assemblages (stations), suggesting that relatively higher grazing mortality on large microphytoplankton (lower $m_{\mathrm{S}} / m_{\mathrm{L}}$ value) is responsible for steeper NBSS slopes (more negative slope). In fact, the raised grazing mortality of large microphytoplankton could be due to their higher growth rate because growth rate and grazing mortality are coupled (Fig. 4). That is, the elevated growth rate of large microphytoplankton could provoke high grazing mortality. Accordingly, this elevated grazing mortality either directly reduced the abundance of large microphytoplankton or released the small ones from grazing. The NBSS slope is consequently steepened. In other words, relatively higher growth rate of large versus small individuals serves as a trigger for higher grazing mortality of large rather than small individuals, which in turn decreases the abundance of the large microphytoplankton and results in a steeper NBSS slope. This mechanism could link the microphytoplankton growth rates to grazing mortality and then size structure.

We further link environmental conditions with the 9 independent variables, using RDA (Fig. 5). Our results suggest that higher phosphate concentration provokes the growth rate of the large individuals (but not the small ones) first, because the nutrient availability tends to induce the bottomup (growth) forces in community dynamics (Power, 1992). The finding that the phosphate concentration plays the most important role here is consistent with the previous study indicating that the ECS is phosphate-limited (Wong et al., 1998). Also recall in our observation that growth rate is the main factor leading to elevated grazing mortality (Fig. 4). The raised growth rate of large phytoplankton would subsequently promote the grazing pressure on their own. The NBSS slope consequently becomes steeper (more negative).

Note that we also observe significant positive correlations between NBSS slope and the growth rate of small individuals $\left(\mu_{\mathrm{S}}^{\prime}\right.$ in Table 2$)$, as well as the relative growth rate of small versus large individuals $\left(\mu_{\mathrm{S}}^{\prime} / \mu_{\mathrm{L}}^{\prime}\right.$ in Table 2$)$ if we had considered two-tail tests. Biologically, the increase in NBSS slope and the growth rate of small individuals ( $\mu_{\mathrm{S}}^{\prime}$ in Table 2) as well as the relative growth rate of small versus large individuals $\left(\mu_{\mathrm{S}}^{\prime} / \mu_{\mathrm{L}}^{\prime}\right.$ in Table 2$)$ should have promoted the abundance of small individuals and consequently steepened the NBSS slope (more negative slope). Thus, the estimated positive coefficients of these two models are spurious correlations that resulted from the covariance between size-specific growth rate and grazing mortality (Fig. 4).

In conclusion, we found that, in relatively higher nutrient environments in the ECS, the grazing pressure was relatively higher on larger individuals; as a consequence, the NBSS slope was more negative (steeper). This is in contrast with the often observed pattern that the NBSS slope of phytoplankton size distribution is flatter in higher nutrient environments (Reul et al., 2008). Such patterns are generally found in the environment where bottom-up control dominates. However, our observations suggest that, during our experiments in the ECS, the top-down control could be more important and may play an important role in determining phytoplankton size structure. Such a kind of top-down effects on size structure is overlooked in the literature and deserves more attention (Brucet et al., 2010; Shurin et al., 2012).

\subsection{Difficulties in testing the MTE in natural phytoplankton assemblages}

While we carried out the experiments to investigate the in situ phytoplankton dynamics to test the MTE, some possible incubation artefacts remain. As pointed by Dolan and McKeon (2005), the grazing behaviour of microzooplankton could be altered by the dilution processes, especially in the most diluted treatments. The microzooplankton in the most diluted treatment would grow slowly and display low grazing rate due to food limitation (Dolan et al., 2000), which could result in overestimation of grazing mortality and underestimation of growth rate at the community level. However, Landry and Calbet (2005) have validated the dilution experiment by finding correspondence between rate estimates from dilution experiments and other isotopic assessments.

In addition, our bottle incubation could potentially reduce the already low density of large predators that likely feed on large microphytoplankton. Such reduction in zooplankton density might have biased our observations. Nevertheless, we collected the water samples directly from the ocean, and they did not pass through any filter while conducting dilution experiments. The density of grazers should be the same as that in natural environments. Besides, when distributing the seawater from a $20 \mathrm{~L}$ container into $2.4 \mathrm{~L}$ bottles, we gently mixed the $20 \mathrm{~L}$ container from time to time in order to make sure the seawater inside the container was well mixed. Accordingly, assuming the predator density in the ocean is well mixed, the grazing mortality of phytoplankton in all size categories should be consistent with the natural condition. In addition, we have observed copepods in our incubation bottles when conducting the experiments, although we did not measure quantitatively their density. Such observation could be evidence to support the occurrence of mesozooplankton in our incubation. Furthermore, we found no significant difference between the grazing impacts of medium size category (grazing impact $=0.942$ ) and that of the large one (grazing impact $=0.813 ; p=0.541$ ). This would suggest that the grazers of phytoplankton in the large size category did occur in our incubation bottles; otherwise the grazing impact of the large particles would be small (growth rate of large size category would largely exceed grazing mortality). Previous studies using size-fractionated dilution experiments also 
support our findings, as their grazing mortality estimates from the $<20 \mu \mathrm{m}$ and $<200 \mu \mathrm{m}$ fractions do not significantly differ (Lessard and Murrell, 1998; Reckermann and Veldhuis, 1997). However, given relatively scarce studies on sizespecific growth rate and grazing mortality, it is not clear how the technical issues of such bottle incubation could affect the size-specific level investigation.

Another difficulty in testing MTE lies in the limited body size range examined in our study. Narrowing the body size range decreases the explanatory power of body size to metabolic rates (Tilman et al., 2004). In our study, about 3 orders of magnitude (about $100 \mathrm{pgC} \mathrm{cell}^{-1}$ to $130000 \mathrm{pgC} \mathrm{cell}^{-1}$ ) of size range were examined, and body size explained only about $37 \%$ of variation, which is much less than the metaanalysis reported in the MTE $(\sim 15$ orders of magnitude). In addition, the phylogenetic structure could play an important role and obscure our finding in scaling as demonstrated in Seibel (2007); if the differences in scaling exponents among phylogeny groups were large, the generality of MTE might be blurred. However, Maranon (2008) found that both the exponents of diatom and dinoflagellate do not differ from 1 , partially suggesting that phylogeny may not be critical for phytoplankton. Nevertheless, studies on natural phytoplankton assemblages remain scarce, and it is difficult to draw a conclusion here.

The final concern is the assumption of no resource limitation in testing MTE (Brown et al., 2004). Nutrient limitation may not be a concern because our incubations all received artificial nutrient amendments and our scaling analyses used only the growth rates measured with a nutrient amendment $(\mu)$. For the issue of light limitation, our samples were taken from surface water $(10 \mathrm{~m}$ depth) and incubated on deck to avoid light limitation, as was done in other studies (Marañón et al., 2007; Marañón, 2008; Huete-Ortega et al., 2012; McManus et al., 2007). Thus, light limitation effects on phytoplankton growth should not be a problem. Our approach is consistent with previous studies (Landry et al., 1995). Nevertheless, we cannot completely rule out the possibility of limitation, such as some trace metals.

\section{Conclusions}

We developed a novel approach to measure size-specific growth rate and mortality for microphytoplankton. On average, the size-specific growth rates and grazing mortality may scale nearly isometrically with body size within assemblage. However, this finding contains high uncertainty because the size-scaling exponent varies substantially among assemblages in the ECS (Fig. 3; Table B2). These results differ from the prediction of MTE. Whether MTE is generally applicable in natural phytoplankton assemblages remains to be tested. More importantly, we find that relatively higher grazing mortality on large microphytoplankton (lower $m_{\mathrm{S}} / m_{\mathrm{L}}$ value) is responsible for steeper NBSS slopes (more negative slopes) (Table 2). Our results indicate that top-down control plays a pivotal role in determining the microphytoplankton NBSS in the ECS. Future studies on phytoplankton size structure should consider top-down in addition to conventionally emphasized bottom-up effects.

\section{Supplementary material related to this article is available online at: http://www.biogeosciences.net/10/ 5267/2013/bg-10-5267-2013-supplement.pdf.}

Acknowledgements. We thank crews of $\mathrm{R} / \mathrm{V}$ ORI and ORII for their help on sampling. Comments from Kuo-Ping Chiang, Tai-Sheng Chiu, Carmen García-Comas, Justin E. Lawrence, Takeshi Miki, and Fuh-Kwo Shiah greatly improved this work. This study was supported by the National Taiwan University, National Science Council of Taiwan, and Academia Sinica.

Edited by: T. Kobari

\section{References}

Agawin, N. S. R., Duarte, C. M., and Agusti, S.: Nutrient and temperature control of the contribution of picoplankton to phytoplankton biomass and production, Limnol. Oceanogr., 45, 591600, 2000.

Allen, A. P., Gillooly, J. F., and Brown, J. H.: Linking the global carbon cycle to individual metabolism, Funct. Ecol., 19, 202213, 2005.

Alvarez, E., Lopez-Urrutia, A., Nogueira, E., and Fraga, S.: How to effectively sample the plankton size spectrum? A case study using FlowCAM, J. Plankton Res., 33, 1119-1133, 2011.

Banavar, J. R., Damuth, J., Maritan, A., and Rinaldo, A.: Supplydemand balance and metabolic scaling, P. Natl. Acad. Sci. USA, 99, 10506-10509, 2002.

Barnes, C., Irigoien, X., De Oliveira, J. A. A., Maxwell, D., and Jennings, S.: Predicting marine phytoplankton community size structure from empirical relationships with remotely sensed variables, J. Plankton Res., 33, 13-24, 2011.

Berner, T., Dubinsky, Z., Wyman, K., and Falkowski, P. G.: Photoadaptation and the "package effect" in Dunaliella tertiolecta (Chlorophyceae), J. Phycol., 25, 70-78, 1989.

Bissinger, J. E., Montagnes, D. J. S., Sharples, J., and Atkinson, D.: Predicting marine phytoplankton maximum growth rates from temperature: Improving on the Eppley curve using quantile regression, Limnol. Oceanogr., 53, 487-493, 2008.

Bolker, B. M., Brooks, M. E., Clark, C. J., Geange, S. W., Poulsen, J. R., Stevens, M. H. H., and White, J.-S. S.: Generalized linear mixed models: a practical guide for ecology and evolution, Trends Ecol. Evol., 24, 127-135, 2009.

Brown, J. H., Gillooly, J. F., Allen, A. P., Savage, V. M., and West, G. B.: Toward a metabolic theory of ecology, Ecology, 85, 17711789, 2004.

Brucet, S., Boix, D., Quintana, X. D., Jensen, E., Nathansen, L. W., Trochine, C., Meerhoff, M., Gascon, S., and Jeppesen, E.: Fac- 
tors influencing zooplankton size structure at contrasting temperatures in coastal shallow lakes: Implications for effects of climate change, Limnol. Oceanogr., 55, 1697-1711, 2010.

Burkill, P. H., Mantoura, R. F. C., Llewellyn, C. A., and Owens, N. J. P.: Microzooplankton grazing and selectivity of phytoplankton in coastal waters, Mar. Biol., 93, 581-590, 1987.

Calbet, A.: The trophic roles of microzooplankton in marine systems, ICES J. Mar. Sci., 65, 325-331, 2008.

Calbet, A. and Landry, M. R.: Phytoplankton growth, microzooplankton grazing, and carbon cycling in marine systems, Limnol. Oceanogr., 49, 51-57, 2004.

Calbet, A., Landry, M. R., and Nunnery, S.: Bacteria-flagellate interactions in the microbial food web of the oligotrophic subtropical North Pacific, Aquat. Microb. Ecol., 23, 283-292, 2001.

Calbet, A., Trepat, I., Almeda, R., Salo, V., Saiz, E., Movilla, J. I., Alcaraz, M., Yebra, L., and Simo, R.: Impact of micro- and nanograzers on phytoplankton assessed by standard and sizefractionated dilution grazing experiments, Aquat. Microb. Ecol., 50, 145-156, 2008.

Cavender-Bares, K. K., Rinaldo, A., and Chisholm, S. W.: Microbial size spectra from natural and nutrient enriched ecosystems, Limnol. Oceanogr., 46, 778-789, 2001.

Cermeño, P., Marañón, E., Rodríguez, J., and Fernádez, E.: Largesized phytoplankton sustain higher carbon-specific photosynthesis than smaller cells in a coastal eutrophic ecosystem, Mar. Ecol.-Prog. Ser., 297, 51-60, 2005.

Chan, Y.-F., Tsai, A.-Y., Chiang, K.-P., and Hsieh, C.-h.: Pigmented nanoflagellates grazing on Synechococcus: seasonal variations and effect of flagellate size in the coastal ecosystem of subtropical western pacific, Microb. Ecol., 58, 548-557, 2009.

Chang, J., Lin, K. H., Chen, K. M., Gong, G. C., and Chiang, K. P.: Synechococcus growth and mortality rates in the East China Sea: range of variations and correlation with environmental factors, Deep-Sea Res. Pt. II, 50, 1265-1278, 2003.

Chen, B. Z. and Liu, H. B.: Relationships between phytoplankton growth and cell size in surface oceans: Interactive effects of temperature, nutrients, and grazing, Limnol. Oceanogr., 55, 965972, 2010.

Chen, B. Z., Liu, H. B., Landry, M. R., Dai, M. H., Huang, B. Q., and Sun, J.: Close coupling between phytoplankton growth and microzooplankton grazing in the western South China Sea, Limnol. Oceanogr., 54, 1084-1097, 2009.

Dolan,, J. R. and McKeon, K.: The reliability of grazing rate estimates from dilution experiments: Have we over-estimated rates of organic carbon consumption by microzooplankton?, Ocean Sci., 1, 1-7, doi:10.5194/os-1-1-2005, 2005.

Dolan, J. R., Gallegos, C. L., and Moigis, A.: Dilution effects on microzooplankton in dilution grazing experiments, Mar. Ecol.Prog. Ser., 200, 127-139, 2000.

Edwards, K. F., Thomas, M. K., Klausmeier, C. A., and Litchman, E.: Allometric scaling and taxonomic variation in nutrient utilization traits and maximum growth rate of phytoplankton, Limnol. Oceanogr., 57, 554-566, 2012.

Eppley, R. W.: Temperature and phytoplankton growth in the sea, Fish. B.-NOAA, 70, 1063-1085, 1972.

Finkel, Z. V.: Light absorption and size scaling of light-limited metabolism in marine diatoms, Limnol. Oceanogr., 46, 86-94, 2001.
Finkel, Z. V., Irwin, A. J., and Schofield, O.: Resource limitation alters the 3/4 size scaling of metabolic rates in phytoplankton, Mar. Ecol.-Prog. Ser., 273, 269-279, 2004.

Froneman, P. W. and McQuaid, C. D.: Preliminary investigation of the ecological role of microzooplankton in the Kariega Estuary, South Africa, Estuar. Coast. Shelf S., 45, 689-695, 1997.

Gaul, W. and Antia, A. N.: Taxon-specific growth and selective microzooplankton grazing of phytoplankton in the Northeast Atlantic, J. Marine Syst., 30, 241-261, 2001.

Glazier, D. S.: Beyond the '3/4-power law': variation in the intraand interspecific scaling of metabolic rate in animals, Biol. Rev., 80, 611-662, 2005.

Glazier, D. S.: A unifying explanation for diverse metabolic scaling in animals and plants, Biol. Rev., 85, 111-138, 2010.

Gong, G. C., Chen, Y. L. L., and Liu, K. K.: Chemical hydrography and chlorophyll a distribution in the East China Sea in summer: Implications in nutrient dynamics, Cont. Shelf Res., 16, 15611590, 1996.

Gong, G. C., Shiah, F. K., Liu, K. K., Wen, Y. H., and Liang, M. H.: Spatial and temporal variation of chlorophyll a, primary productivity and chemical hydrography in the southern East China Sea, Cont. Shelf Res., 20, 411-436, 2000.

Gong, G. C., Wen, Y. H., Wang, B. W., and Liu, G. J.: Seasonal variation of chlorophyll a concentration, primary production and environmental conditions in the subtropical East China Sea, DeepSea Res. Pt. II, 50, 1219-1236, 2003.

Gutiérrez-Rodríguez, A., Latasa, M., Mourre, B., and Laws, E. A.: Coupling between phytoplankton growth and microzooplankton grazing in dilution experiments: potential artefacts, Mar. Ecol.Prog. Ser., 383, 1-9, 2009.

Gutiérrez-Rodríguez, A., Latasa, M., Scharek, R., Massana, R., Vila, G., and Gasol, J. M.: Growth and grazing rate dynamics of major phytoplankton groups in an oligotrophic coastal site, Estuar. Coast. Shelf S., 95, 77-87, 2011.

Hendriks, A. J.: The power of size: A meta-analysis reveals consistency of allometric regressions, Ecol. Model., 205, 196-208, 2007.

Huete-Ortega, M., Calvo-Díaz, A., Graña, R., Mouriño-Carballido, B., and Marañón, E.: Effect of environmental forcing on the biomass, production and growth rate of size-fractionated phytoplankton in the central Atlantic Ocean, J. Marine. Syst., 88, 203-213, 2011.

Huete-Ortega, M., Cermeño, P., Calvo-Díaz, A., and Marañón, E.: Isometric size-scaling of metabolic rate and the size abundance distribution of phytoplankton, P. Roy. Soc. B-Biol. Sci., 279, 1815-1823, 2012.

Ide, K., Takahashi, K., Kuwata, A., Nakamachi, M., and Saito, H.: A rapid analysis of copepod feeding using FlowCAM, J. Plankton Res., 30, 275-281, 2008.

Irwin, A. J., Finkel, Z. V., Schofield, O. M. E., and Falkowski, P. G.: Scaling-up from nutrient physiology to the size-structure of phytoplankton communities, J. Plankton Res., 28, 459-471, 2006.

Jiao, N. Z., Yang, Y. H., Koshikawa, H., and Watanabe, M.: Influence of hydrographic conditions on picoplankton distribution in the East China Sea, Aquat. Microb. Ecol., 30, 37-48, 2002.

Juhl, A. R. and Murrell, M. C.: Interactions between nutrients, phytoplankton growth, and microzooplankton grazing in a Gulf of Mexico estuary, Aquat. Microb. Ecol., 38, 147-156, 2005. 
Key, T., McCarthy, A., Campbell, D. A., Six, C., Roy, S., and Finkel, Z. V.: Cell size trade-offs govern light exploitation strategies in marine phytoplankton, Environ. Microbiol., 12, 95-104, 2010.

Kiørboe, T.: Turbulence, phytoplankton cell size, and the structure of pelagic food webs, Adv. Mar. Biol., 29, 1-72, 1993.

Landry, M. R. and Calbet, A.: Reality checks on microbial food web interactions in dilution experiments: responses to the comments of Dolan and McKeon, Ocean Sci., 1, 39-44, 2005, http://www.ocean-sci.net/1/39/2005/.

Landry, M. R. and Hassett, R. P.: Estimating the grazing impact of marine micro-zooplankton, Mar. Biol., 67, 283-288, 1982.

Landry, M. R., Kirshtein, J., and Constantinou, J.: A refined dilution technique for measuring the community grazing impact of microzooplankton, with experimental tests in the central equatorial Pacific, Mar. Ecol.-Prog. Ser., 120, 53-63, 1995.

Landry, M. R., Constantinou, J., Latasa, M., Brown, S. L., Bidigare, R. R., and Ondrusek, M. E.: Biological response to iron fertilization in the eastern equatorial Pacific (IronEx II), III. Dynamics of phytoplankton growth and microzooplankton grazing, Mar. Ecol.-Prog. Ser., 201, 57-72, 2000.

Latasa, M., Morán, X. A. G., Scharek, R., and Estrada, M.: Estimating the carbon flux through main phytoplankton groups in the northwestern Mediterranean, Limnol. Oceanogr., 50, 14471458, 2005.

Legendre, P. and Legendre, L.: Numerical ecology, 2nd English Edn., Elsevier Science B. V., Amsterdam, the Netherlands, i-xv, 1-853, 1998.

Lessard, E. J. and Murrell, M. C.: Microzooplankton herbivory and phytoplankton growth in the northwestern Sargasso Sea, Aquat. Microb. Ecol., 16, 173-188, 1998.

Li, W. K. W.: Macroecological patterns of phytoplankton in the northwestern North Atlantic Ocean, Nature, 419, 154-157, 2002.

Lie, A. A. Y. and Wong, C. K.: Selectivity and grazing impact of microzooplankton on phytoplankton in two subtropical semienclosed bays with different chlorophyll concentrations, J. Exp. Mar. Biol. Ecol., 390, 149-159, 2010.

Litchman, E., Klausmeier, C. A., Schofield, O. M., and Falkowski, P. G.: The role of functional traits and trade-offs in structuring phytoplankton communities: scaling from cellular to ecosystem level, Ecol. Lett., 10, 1170-1181, 2007.

Lopez-Urrutia, A., San Martin, E., Harris, R. P., and Irigoien, X.: Scaling the metabolic balance of the oceans, P. Natl. Acad. Sci. USA, 103, 8739-8744, 2006.

Maguer, J. F., L'Helguen, S., Waeles, M., Morin, P., Riso, R., and Caradec, J.: Size-fractionated phytoplankton biomass and nitrogen uptake in response to high nutrient load in the North Biscay Bay in spring, Cont. Shelf Res., 29, 1103-1110, 2009.

Marañón, E.: Inter-specific scaling of phytoplankton production and cell size in the field, J. Plankton Res., 30, 157-163, 2008.

Marañón, E., Cermeno, P., Rodriguez, J., Zubkov, M. V., and Harris, R. P.: Scaling of phytoplankton photosynthesis and cell size in the ocean, Limnol. Oceanogr., 52, 2190-2198, 2007.

Marañón, E., Cermeño, P., Latasa, M., and Tadonléké, R. D.: Temperature, resources, and phytoplankton size structure in the ocean, Limnol. Oceanogr., 57, 1266-1278, 2012.

Marañón, E., Cermeño, P., López-Sandoval, D. C., RodríguezRamos, T., Sobrino, C., Huete-Ortega, M., Blanco, J. M., and Rodríguez, J.: Unimodal size scaling of phytoplankton growth and the size dependence of nutrient uptake and use, Ecol. Lett.,
16, 371-379, 2013.

Marba, N., Duarte, C. M., and Agusti, S.: Allometric scaling of plant life history, P. Natl. Acad. Sci. U. S. A., 104, 15777-15780, 2007.

Marquis, E., Niquil, N., and Dupuy, C.: Does the study of microzooplankton community size structure effectively define their dynamics? Investigation in the Bay of Biscay (France), J. Plankton Res., 33, 1104-1118, 2011.

McCoy, M. W. and Gillooly, J. F.: Predicting natural mortality rates of plants and animals, Ecol. Lett., 11, 710-716, 2008.

McManus, G. B., Costas, B. A., Dam, H. G., Lopes, R. M., Gaeta, S. A., Susini, S. M., and Rosetta, C. H.: Microzooplankton grazing of phytoplankton in a tropical upwelling region, Hydrobiologia, 575, 69-81, 2007.

Montagnes, D. J. S., Barbosa, A. B., Boenigk, J., Davidson, K., Jurgens, K., Macek, M., Parry, J. D., Roberts, E. C., and Simek, K.: Selective feeding behaviour of key free-living protists: avenues for continued study, Aquat. Microb. Ecol., 53, 83-98, 2008.

Moran, X. A. G., Lopez-Urrutia, A., Calvo-Diaz, A., and Li, W. K. W.: Increasing importance of small phytoplankton in a warmer ocean, Global Change Biol., 16, 1137-1144, 2010.

Murrell, M. C., Stanley, R. S., Lores, E. M., DiDonato, G. T., and Flemer, D. A.: Linkage between microzooplankton grazing and phytoplankton growth in a Gulf of Mexico estuary, Estuaries, 25, 19-29, 2002.

Platt, T. and Denman, K.: Organization in pelagic ecosystem, Helgoländer wissenschaftliche Meeresuntersuchungen, 30, 575581, 1977.

Power, M. E.: Top-down and bottom-up forces in food webs- do plants have primacy?, Ecology, 73, 733-746, 1992.

Reckermann, M. and Veldhuis, M. J. W.: Trophic interactions between picophytoplankton and micro- and nanozooplankton in the western Arabian Sea during the NE monsoon 1993, Aquat. Microb. Ecol., 12, 263-273, 1997.

Reich, P. B., Tjoelker, M. G., Machado, J. L., and Oleksyn, J.: Universal scaling of respiratory metabolism, size and nitrogen in plants, Nature, 439, 457-461, 2006.

Reul, A., Rodriguez, V., Jimenez-Gomez, F., Blanco, J. M., Bautista, B., Sarhan, T., Guerrero, F., Ruiz, J., and GarciaLafuente, J.: Variability in the spatio-temporal distribution and size-structure of phytoplankton across an upwelling area in the NW-Alboran Sea, (W-Mediterranean), Cont. Shelf Res., 25, 589608, 2005.

Reul, A., Rodriguez, J., Guerrero, F., Gonzalez, N., Vargas, J. M., Echevarria, F., Rodriguez, V., and Jimenez-Gomez, F.: Distribution and size biomass structure of nanophytoplankton in the Strait of Gibraltar, Aquat. Microb. Ecol., 52, 253-262, 2008.

Ricklefs, R. E.: Evolutionary theories of aging: Confirmation of a fundamental prediction, with implications for the genetic basis and evolution of life span, Am. Nat., 152, 24-44, 1998.

Safi, K. A., Brian Griffiths, F., and Hall, J. A.: Microzooplankton composition, biomass and grazing rates along the WOCE SR3 line between Tasmania and Antarctica, Deep-Sea Res. Pt. I, 54, 1025-1041, 2007.

Savage, V. M., Deeds, E. J., and Fontana, W.: Sizing up allometric scaling theory, PLoS Comput. Biol., 4, e1000171, doi:10.1371/journal.pcbi.1000171, 2008.

Seibel, B. A.: On the depth and scale of metabolic rate variation: scaling of oxygen consumption rates and enzymatic activity in 
the Class Cephalopoda (Mollusca), J. Exp. Biol., 210, 1-11, 2007.

Sheldon, R. W., Sutcliff, W. H., and Prakash, A.: Size distribution of particles in the ocean, Limnol. Oceanogr., 17, 327-340, 1972.

Shurin, J. B., Clasen, J. L., Greig, H. S., Kratina, P., and Thompson, P. L.: Warming shifts top-down and bottom-up control of pond food web structure and function, Philos. T. Roy. Soc.-B., 367, 3008-3017, 2012.

Stolte, W., McCollin, T., Noordeloos, A. A. M., and Riegman, R.: Effect of nitrogen-source on the size distribution within marinephytoplankton populations, J. Exp. Mar. Biol. Ecol., 184, 83-97, 1994.

Strom, S. L.: Novel interactions between phytoplankton and microzooplankton: their influence on the coupling between growth and grazing rates in the sea, Hydrobiologia, 480, 41-54, 2002.

Strom, S. L. and Welschmeyer, N. A.: Pigment-specific rates of phytoplankotn growth and micrzooplankton grazing in the open subarctic pacific-ocean, Limnol. Oceanogr., 36, 50-63, 1991.

Teixeira, I. G., Figueiras, F. G., Crespo, B. G., and Piedracoba, S.: Microzooplankton feeding impact in a coastal upwelling system on the NW Iberian margin: The Ría de Vigo, Estuar. Coast. Shelf S., 91, 110-120, 2011.

Thingstad, T. F., Ovreas, L., Egge, J. K., Lovdal, T., and Heldal, M.: Use of non-limiting substrates to increase size; a generic strategy to simultaneously optimize uptake and minimize predation in pelagic osmotrophs?, Ecol. Lett., 8, 675-682, 2005.

Tilman, D., Hillerislambers, J., Harpole, S., Dybzinski, R., Fargione, J., Clark, C., and Lehman, C.: Does metabolic theory apply to community ecology? It's a matter of scale, Ecology, 85, 1797-1799, 2004.
Tsai, A. Y., Gong, G. C., Sanders, R. W., Chen, W. H., Chao, C. F., and Chiang, K. P.: Importance of bacterivory by pigmented and heterotrophic nanoflagellates during the warm season in a subtropical western Pacific coastal ecosystem, Aquat. Microb. Ecol., 63, 9-18, 2011.

Verdy, A., Follows, M., and Flierl, G.: Optimal phytoplankton cell size in an allometric model, Mar. Ecol.-Prog. Ser., 379, 1-12, 2009.

Wong, G. T. F., Gong, G. C., Liu, K. K., and Pai, S. C.: "Excess nitrate" in the East China Sea, Estuar. Coast. Shelf S., 46, 411418, 1998.

Yvon-Durocher, G., Montoya, J. M., Trimmer, M., and Woodward, G. U. Y.: Warming alters the size spectrum and shifts the distribution of biomass in freshwater ecosystems, Global Change Biol., 17, 1681-1694, 2011.

Zhang, J., Liu, S. M., Ren, J. L., Wu, Y., and Zhang, G. L.: Nutrient gradients from the eutrophic Changjiang (Yangtze River) Estuary to the oligotrophic Kuroshio waters and re-evaluation of budgets for the East China Sea Shelf, Prog. Oceanogr., 74, 449478, 2007.

Zhang, L. Y., Sun, J., Liu, D. Y., and Yu, Z. S.: Studies on growth rate and grazing mortality rate by microzooplankton of sizefractionated phytoplankton in spring and summer in the Jiaozhou Bay, China, Acta. Oceanol. Sin., 24, 85-101, 2005. 